\title{
Phase II study of short-time oxaliplatin, capecitabine and epirubicin (EXE) as first-line therapy in patients with non-resectable gastric
}

\section{cancer}

\author{
KR Schønnemann", , HA Jensen', M Yilmaz ${ }^{3}$, BV Jensen ${ }^{2}, O$ Larsen $^{2}$ and P Pfeiffer' \\ 'Department of Oncology, Odense University Hospital, Odense C 5000, Denmark; ${ }^{2}$ Department of Oncology, Herlev Hospital, Copenhagen, Denmark; \\ ${ }^{3}$ Department of Oncology, Ålborg Hospital, Copenhagen, Denmark
}

Epirubicin, cisplatin and continuous infusion of 5-FU is a widely used palliative regimen in patients with gastric cancer. If cisplatin is substituted by oxaliplatin and 5-FU by capecitabine this regimen can be administered in the outpatient setting. Dose-limiting toxicity of oxaliplatin is peripheral sensory neuropathy and it is recommended to give oxaliplatin as a 120 min infusion. However, in patients with colorectal cancer a $30 \mathrm{~min}$ infusion of oxaliplatin can safely be administered without increasing neurotoxicity, standard infusion time is 30 min at our departments. In our phase I study the recommended doses of EXE was established (Dupont et al, 2006). Patients with non-resectable gastric adenocarcinoma were eligible. Patients received EXE (epirubicin $50 \mathrm{mg} \mathrm{m}^{-2}$ day I; capecitabine $1000 \mathrm{mg} \mathrm{m}^{-2}$ day $^{-1}$ continuously and oxaliplatin $130 \mathrm{mg} \mathrm{m}^{-2}$ day I) as outpatient therapy every third week for a maximum of 8 cycles. From June 2004 to September 2005, we enroled 54 patients. Median age was 60 years (31-74 years) Median number of courses was $6(I-8)$. Response rate was 45\%. Median PFS was 6.8 (5.2-7.9) months and median survival was I0.I (7.9-II.I) months. Most important grade 3 toxicities were as follows: nausea, vomiting, and diarrhoea (6\%). Neurotoxicity grade 2 was seen in $36.5 \%$. We therefore conclude, that EXE every third week is a convenient regimen that easily can be administrated in the outpatient setting but the regimen needs further evaluation in a phase III study.

British Journal of Cancer (2008) 99, 858-86।. doi:I0.1038/sj.bjc.6604569 www.bjcancer.com

Published online 26 August 2008

(c) 2008 Cancer Research UK

Keywords: advanced gastric cancer; oxaliplatin; capecitabine; epirubicin; EXE

Gastric cancer (GC) remains a significant global health problem and is one of the most frequent causes of cancer-related deaths. Although the incidence has been declining in Europe during the last century it is still the fifth most common cancer and an estimated 171000 new cases of GC will be diagnosed each year (Boyle and Ferlay, 2005). The prognosis is very poor, with a 5-year overall survival of approximately $10 \%$ in Denmark (Coleman et al, 2003). The only potentially curative treatment for GC is surgery, but unfortunately most cases are diagnosed at an advanced stage because of very few organ-specific symptoms and therefore only about $20 \%$ of the patients are suitable for curative surgery (Janunger et al, 2001).

Therefore the need for palliative treatment is huge for these patients. The efficiency of palliative chemotherapy is widely accepted. Data from randomised studies have shown that combination chemotherapy results in a significant survival advantage and improves quality of life in patients with advanced GC (Murad et al, 1993; Pyrhonen et al, 1995; Glimelius et al, 1997; Wagner et al, 2006).

In the past decade a number of effective chemotherapy regimens have been established worldwide. However, these studies have not

*Correspondence: Dr KR Schønnemann; E-mail: katrinesch@gmail.com Received 7 April 2008; revised 8 July 2008; accepted 23 July 2008; published online 26 August 2008 resulted in a standard regimen for gastric cancer, but the backbone of these regimens is most often a combination of 5-fluorouracil (5-FU) and platinum. In Europe ECF (epirubicin $50 \mathrm{mg} \mathrm{m}^{-2}$ day 1, cisplatin $60 \mathrm{mg} \mathrm{m}^{-2}$ day 1 and continuous infusion (CVI) of 5-FU $200 \mathrm{mg} \mathrm{m}^{-2}$ daily) is widely used as it was shown that ECF improves response rate and prolongs survival when compared with FAMtx which was considered to be a standard therapy a decade ago (Webb et al, 1997; Waters et al, 1999).

We sought to find a regimen that was comparable with ECF in efficacy, easy to administer in an outpatient setting and with low toxicity.

Therapy with 5-FU requires a central venous catheter which is associated with risk of venous thromboses and infection (Findlay et al, 1994; Evans et al, 1996). Capecitabine is an oral fluoropyrimidine, which is absorbed from the gastrointestinal tract as an intact molecule and afterwards converted into 5-FU in a cascade of three enzymatic steps (Miwa et al, 1998). Capecitabine is a well-established alternative which simplifies the administration of 5-FU and overcomes the problem with the central venous catheter.

Another cornerstone in ECF is cisplatin, which is highly emetic and in addition intravenous hydration is required to prevent renal toxicity.

Oxaliplatin is a third-generation platinum that easily can be administered in outpatients without hydration. When compared 
with cisplatin, oxaliplatin has a better safety profile with regard to renal toxicity and emesis. Recent studies have shown synergism between oxaliplatin and 5-FU and a combination of these two drugs has proven effective as first- or second-line treatment for advanced colorectal cancer (De Gramont et al, 2000; Raymond et al, 2001; Cassidy et al, 2004). The dose-limiting toxicity of oxaliplatin is peripheral sensory neuropathy, which is reversible but cumulative. Usually it is recommended to give oxaliplatin as a $120 \mathrm{~min}$ infusion to minimize peripheral neuropathy. However, we have recently in patients with colorectal cancer demonstrated that a 30 min infusion apparently does not result in more neurotoxicity (Pfeiffer et al, 2003, 2006).

We therefore used 30 min infusion of oxaliplatin in both our phase I and phase II trial (Dupont et al, 2006). The primary aims of our phase II study were to evaluate response rate and toxicity of EXE in patients with advanced gastric cancer. Secondary end points were progression-free survival and overall survival.

\section{MATERIALS AND METHODS}

\section{Patient selection}

Eligible patients were required to have histological verified nonresectable gastric or gastro-oesophageal junction adenocarcinoma and at least one measurable lesion according to RECIST criteria.

Eligibility criterias also included WHO performance status $0-2$; age between 18 and 75 years; estimated life expectancy of at least 3 months; adequate hepatic function (serum bilirubin $<1.5 \times$ upper normal limit (UNL); transaminase $<3 \times \mathrm{UNL}$, however in cases of livermetastases, there was no upper limit for transaminases); adequate renal function (calculated creatinine clearance $>30 \mathrm{ml} \mathrm{min}^{-1}$ by the Cockroft and Gault formula); adequate haematological function (neutrophil count $>1.5 \times 10^{9} 1^{-1}$; platelets $>100 \times 10^{9} 1^{-1}$ and no prior chemotherapy other than adjuvant chemotherapy, completed at least six months before inclusion.

Other inclusion criterias were ability to tolerate and comply with oral medication, no sign of peripheral neuropathy, no co-existent severe medical illness, no sign of brain metastases and no concomitant treatment with other anticancer therapy. Females were not included if they were pregnant or lactating.

The study was approved by the local ethics committee and Danish health authority and all participants gave written informed consent before entering the study.

\section{Study design and treatment}

Patients were planned to receive a combination of epirubicin $50 \mathrm{mg} \mathrm{m}^{-2}$ as a $20 \mathrm{~min}$. i.v. infusion day 1 , oxaliplatin $130 \mathrm{mg} \mathrm{m}^{-2}$ as a $30 \mathrm{~min}$. i.v. infusion day 1 and capecitabine $500 \mathrm{mg} \mathrm{m}^{-2} \times 2$ daily continuously each 3 weeks (Dupont et al, 2006).

Therapy was repeated every 3 weeks up to a maximum of eight cycles of treatment unless stopped before because of disease progression, unacceptable toxicity or patient refusal.

Reduction of $25 \%$ in all drug doses was recommended in the event of occurrence of febrile neutropenia, grade 4 thrombocytopenia (platelet count $<25 \times 10^{9} 1^{-1}$ ) or grade 4 neutropenia (absolute neutrophil count $<0.5 \times 10^{9} 1^{-1}$ ), grade 3-4 mucositis, diarrhoea, or nausea/vomiting in spite of optimal antiemetic treatment. Toxicity was graded according to NCIC-CTC version 2.0. Peripheral sensitive neuropathy to oxaliplatin was graded according to the following oxaliplatin-specific scale. Grade 1, parestesias/hypoesthesias of short duration with complete recovery before the next cycle; grade 2, parestesias/hypoesthesias persisting between two cycles without functional impairment; and grade 3 permanent parestesias/hypoesthesias resulting in functional impairment (Caussanel et al, 1990). In case of grade 2 neuropathy oxaliplatin was reduced $25 \%$.

\section{Patient evaluation}

Baseline evaluation included physical examination, assessment of medical history, evaluation of performance status and blood counts. During treatment patients were evaluated before each cycle of therapy with the above parameters. All patients had an abdominal and thoracic CT-scan performed at baseline and every third cycle to assess tumour response. Tumour response was classified according to RECIST guidelines and confirmed as lasting longer than 4 weeks.

After the end of the therapy patients were followed every third month until progression or death.

\section{Statisistical methods}

The primary end point of this phase II study was response rate to EXE and secondary end points were progression-free survival (PFS), and overall survival (OS). Progression-free survival was defined as the time from inclusion to progressive disease occurred (according to the RECIST criteria) or death of any cause. Overall survival was defined as the time from inclusion to death of any cause. Progression-free survival and OS were updated until 1 September 2007.

Non-parametric statistics was applied. All median values are followed by range in brackets. After cessation of treatment patients without documented progression were followed every 3 months with clinical and radiological evaluation. Progression-free survival and OS were generated according to the Kaplan-Meier method. Data were recorded and analysed in a Medlog ${ }^{\mathbb{R}}$ database. All analyses were done on an intention-to-treat population.

\section{RESULTS}

\section{Patient charasteristics}

Between June 2004 and August 2005, 54 patients with gastric and gastro-oesophageal adenocarcinoma were treated at three Danish oncology centres. Baseline patient characteristics are shown in Table 1. The median age was 59 years (range, 31-74 years). Performance status was 0 in 25 patients, one in 26 patients and two in three patients. No patients had previously received adjuvant chemotherapy or radiotherapy. Forty-three patients had adenocarcinoma located in cardia and 11 patients had adenocarcinoma located in the corpus or antrum of the stomach. Nine patients (17\%) had locally advanced disease and 45 patients $(83 \%)$ had metastatic disease. Twenty-four patients had more than one organ involved (range, 2-4).

\section{Toxicity}

Fifty-three patients were evaluable for toxicity as one died of gastrointestinal bleeding 5 days after the first cycle of chemotherapy. Worst toxicity for all patients and all cycles are listed in Table 2. Neutropenia was the principal haematologic toxicity, $13 \%$ of the patients experienced grade 2 neutropenia, $15 \%$ grade 3 and $2 \%$ grade 4 neutropenia, but no patient had febrile neutropenia. Infection grade $2-3$ without neutropenia was seen in $12 \%$. In general grade 4 toxicity was rare, one patient experienced grade 4 neutropenia and one had vomiting in grade 4 .

Non-haematologic toxicities were primary grade 2 toxicity, diarrhoea (13\%), nausea (32\%), vomiting (22\%), hand food syndrome (PPE) (10\%) and peripheral neuropathy (36\%). No patients had peripheral neuropathy or PPE grade 3 or 4 , and only 6 , 4, and $6 \%$ had diarrhoea, vomiting or nausea grade 3 , respectively. Except for the patient who died of gastrointestinal bleeding there was no treatment-related death in this study. 


\section{Efficacy}

The median number of EXE was 6 (range, 1-8), 19 patients completed eight cycles of treatment. The reasons for discontinuation of EXE were progressive disease or deterioration of health $(n=21)$, toxicity $(n=7)$, patient refusal $(n=5)$ and other $(n=2)$. One patient had complete response and 23 obtained partial response, giving an overall response rate of $45 \%$ in the ITT population.

Progression-free survival was 6.8 months (range, 5.2-7.9) and median survival was 10.1 months (range, 7.9-11.1) (Figure 1). Five patients are still alive 24-37 months after inclusion, one without active disease and four patients who have either had surgery or second- and third-line chemotherapy after progression.

Table I Patient characteristics at baseline

\begin{tabular}{|c|c|}
\hline Characteristic & $\mathbf{N}$ \\
\hline \multicolumn{2}{|l|}{ Age } \\
\hline Median & 59 \\
\hline Range & $31-74$ \\
\hline \multicolumn{2}{|l|}{ WHO performance status } \\
\hline 0 & 25 \\
\hline I & 26 \\
\hline 2 & 3 \\
\hline \multicolumn{2}{|l|}{ Location } \\
\hline Cardia & 43 \\
\hline Corpus & 11 \\
\hline Prior adjuvant chemotherapy & 0 \\
\hline \multicolumn{2}{|l|}{ No. of organs involved } \\
\hline 1 & 30 \\
\hline 2 & 17 \\
\hline$>3$ & 7 \\
\hline \multicolumn{2}{|l|}{ Stage } \\
\hline Locally advanced disease & 9 \\
\hline Metastatic disease & 45 \\
\hline \multicolumn{2}{|l|}{ Status of primary tumour } \\
\hline RO resection & 9 \\
\hline RI resection & 2 \\
\hline R2 resection & 4 \\
\hline No surgery & 39 \\
\hline Increased alkaline phosphatase $\left(>300 \mathrm{UI}^{-1}\right)$ & 4 \\
\hline Increased ALAT $\left(O \cup \mathrm{I}^{-1}\right)$ & 8 \\
\hline
\end{tabular}

Table 2 Worst toxicity after median 6 cycles of EXE

\begin{tabular}{lccc}
\hline & $\begin{array}{c}\text { Grade 2 } \\
\mathbf{n}(\%)\end{array}$ & $\begin{array}{c}\text { Grade 3 } \\
\mathbf{n ~ ( \% ) ~}\end{array}$ & $\begin{array}{c}\text { Grade 4/5 } \\
\mathbf{n}(\%)\end{array}$ \\
\hline Haematologic toxicity & & & \\
Neutropenia & $7(I 3)$ & $8(15)$ & $1(2)$ \\
Thrombocytopenia & $1(2)$ & $1(2)$ & 0 \\
Infection (no neutropenia) & $3(6)$ & $3(6)$ & 0 \\
Febrile neutropenia & 0 & 0 & 0 \\
Nonhaematologic toxicity & & & \\
Diarrhoea & $7(13)$ & $3(6)$ & 0 \\
PPE & $5(10)$ & 0 & 0 \\
Nausea & $17(32)$ & $3(6)$ & 0 \\
Vomiting & $12(22)$ & $2(4)$ & $1(2)$ \\
Neuropathy & $19(36)$ & 0 & 0 \\
Bleeding & & & $1(2)$ \\
\hline
\end{tabular}

\section{DISCUSSION}

Combination chemotherapy prolongs survival and improves quality of life in patients with advanced GC but still they have a poor prognosis and no standard regimen has yet been established.

In many areas of Europe, ECF has been regarded as a reference regimen in patients with advanced gastric or gastrooesophageal cancer as randomized studies have confirmed a high response rate around $45 \%$ and long overall survival around 9-10 months (Webb et al, 1997; Ross et al, 2002).

The introduction of the new anticancer drugs oxaliplatin and capecitabine made it possible to overcome problems with hydration and central venous catheter. A large randomized phase lll study, REAL-2, used ECF as control and substituted cisplatin with oxaliplatin and CVI 5-FU with capecitabine in a $2 \times 2$ factorial design. An impressive 1002 patients were enroled in REAL-2. Response rates were highest in the EOX group (47.9\%) but did not differ significantly between the four groups. There was a nonsignificant difference in PFS among the groups, but there was a trend towards prolonged OS in patients receiving oxaliplatin and capecitabine EOX (Cunningham et al, 2008). In another phase III study, 220 patients were randomised to receive 24 -h infusion 5 -FU, leukovorin and cisplatin or 24-h infusion 5-FU, leukovorin and oxaliplatin (FLO). The authors also observed a trend towards a longer TTP in the FLO arm (median 5, 7 vs 3.8 months) (Al-Batran et al, 2006). Recently, a phase II study with 36 patients also evaluated a therapy with epirubicin, oxaliplatin and 5-FU. The response rate was $46 \%$, PFS was 8.2 months and OS 12.2 months (Neri et al, 2007) Toxicity profile was very similar to the data in this study.

In recent years, ongoing or completed studies are evaluating new drugs or combinations of drugs in locally advanced or metastatic gastric cancer. Docetaxel, one of the 'new' drugs, was
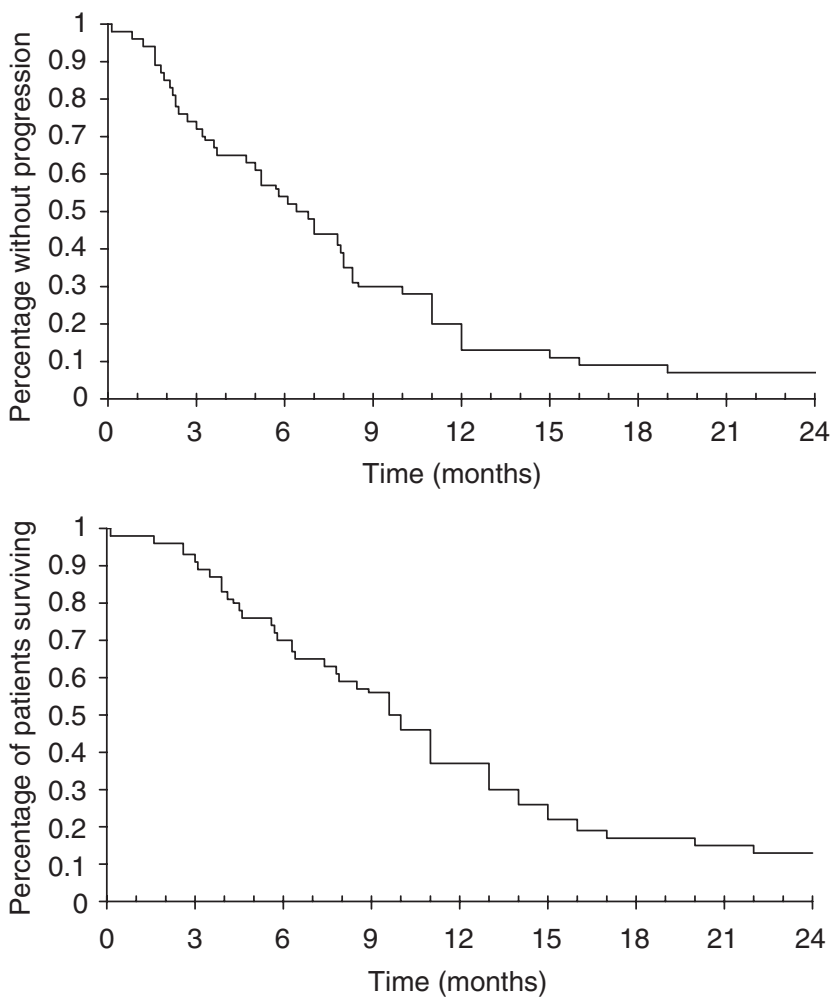

Figure I Time-to-progression and overall survival. Kaplan-Meier curves of time-to-progression (median 6.8 months; $95 \%$ Cl 5.2-7.9 months) and overall survival (median I0.I months; $95 \% \mathrm{Cl} 7.9-1 \mathrm{I} .1$ months). 
evaluated as first-line therapy in a phase III study (V325) with 457 patients receiving docetaxal, cisplatin and 5-FU (DCF) or cisplatin and 5-FU (CF). TTP (5.6 vs 3.7 months) and OS (9.2 vs 8.6 months) were significantly longer for patients receiving DCF (Van Custem et al, 2006). Docetaxel has also been used in combination with capecitabine, irinotecan and epirubicin in different phase II studies. An ongoing phase I and II study in five Danish oncology centres evaluates a combination of docetaxel, epirubicin and capecitabine. The primary end point for phase I is dose-limited toxicity. Primary end point for phase II study is response rate and secondary end points are PFS and OS.

The aims of the present phase II study, was to confirm the efficacy, convenience and tolerability of short-time EXE. We found a promising response rate of $46 \%$, PFS of 6.8 months and OS of
10.1 months and all these efficacy data are comparable to the data observed in similar studies.

Short-time EXE is very well tolerated. Only seven patients $(13 \%)$ stopped chemotherapy because of toxicity. Worst haematologic toxicity was neutropenia (grade 3-4 toxicity in 17 patients) but no patient had febrile neutropenia. Non-haematologic toxicity was primarily diarrhoea, nausea and vomiting but only two patients experienced nausea/ vomiting grade 3-4. Despite the fact that oxaliplatin was infused in $30 \mathrm{~min}$ no patient developed peripheral neuropathy grade 3 and no patient experienced laryngopharyngeal dysaesthesia.

We therefore conclude, that a combination of epirubicin, capecitabine and oxaliplatin every third week is a convenient regimen that easily can be administrated in the outpatient setting but the regimen needs further evaluation in a phase III study.

\section{REFERENCES}

Al-Batran S, Hartmann J, Probst S, Hofheinz R, Stoehlmacher J, Schmalenberg H, Hollerbach S, Schuch G, Homann N, Jäger E (2006) ASCO Annual Meeting Proceedings Part I. J Clin Oncol Vol 24, No. 18S (June 20 Suppl): LBA4016

Boyle P, Ferlay J (2005) Cancer incidence and mortality in Europe, 2004. Ann Oncol 16: 481-488

Cassidy J, Tabernero J, Twelves C, Brunet R, Butts C, Conroy T, Debraud F, Figer A, Grossmann J, Sawada N, Schöffski P, Sobrero A, Van Cutsem E, Díaz-Rubio E (2004) Xelox/capecitabine plus oxaliplatin): active first-line therapy for patients with metastatic colorectal cancer. J Clin Oncol 22(11): 2084-2091

Caussanel JP, Levi F, Brienza S, Misset JL, Itzhaki M, Adam R, Milano G, Hecquet B, Mathé G (1990) Phase I trial of 5-day continuous venous infusion of oxaliplatin at circadian rythm modulated rate compared with constant rate. J Natl Cancer Inst 82: 1046-1050

Coleman MP, Gatta G, Verdecchia A, Estève J, Sant M, Storm H, Allemani C, Ciccolallo L, Santaquilani M, Berrino F, EUROCARE Working Group (2003) Eurocare-3 summery: cancer survival in Europe at the end of the 20th century. Ann Oncol 14(Suppl 5): 128-149

Cunningham D, Starling N, Rao S, Iveson T, Nicolson M, Coxon F, Middleton G, Daniel F, Oates J, Norman AR, Upper Gastrointestinal Clinical Studies Group of the National Cancer Research Institute of the United Kingdom (2008) Capecitabine and oxaliplatin for advanced oesophagogastric cancer. $N$ Engl J Med 358: $36-46$

de Gramont A, Figer A, Seymour M, Homerin M, Hmissi A, Cassidy J, Boni C, Cortes-Funes H, Cervantes A, Freyer G, Papamichael D, Le Bail N, Louvet C, Hendler D, de Braud F, Wilson C, Morvan F, Bonetti A (2000) Leucovorin and fluorouracil with or without oxaliplatin as first-line treatment in advanced colorectal cancer. J Clin Oncol 18: 2938-2947

Dupont J, Jensen HA, Jensen BV, Pfeiffer P (2006) Phase I study of shorttime oxaliplatin, capecitabine and epirubicin (EXE) as first line therapy in patients with non-resectable gastric cancer. Acta Oncol 46: 330-335

Evans TR, Lofts Fj, Mansi JL, Glees JP, Dalgleish AG, Knight MJ (1996) A phase II study of continous infusion 5-fluorouracil with cisplatin and epirubicin in inoperable pancreatic cancer. Br J Cancer 73: 1260-1264

Findlay M, Cunningham D, Norman A, Mansi J, Nicolson M, Hickish T, Nicolson V, Nash A, Sacks N, Ford H et al (1994) A phase II study in advanced gastro-oesophageal cancer using epirubicin and cisplatin in combination with continous infusion 5-fluorouracil (ECF). Ann Oncol 5: $609-616$

Glimelius B, Ekstrom K, Hoffman K, Graf W, Sjödén PO, Haglund U, Svensson C, Enander LK, Linné T, Sellström H, Heuman R (1997) Randomized comparison between chemotherapy plus best surportive care with bestsurportive care in advanced gastric cancer. Ann Oncol 8: 163-168

Janunger KG, Hafström L, Nygren P, Glimelius B, SBU-group. Swedish Council of Technology Assessment in Health Care (2001) A systematic overview of chemotherapy effects in gastric cancer. Acta Oncol 2/3: 309-326

Miwa M, Ura M, Nishida M, Sawada N, Ishikawa T, Mori K, Shimma N, Umeda I, Ishitsuka H (1998) Design of a novel oral fluoropyrimidine carbamate, capecitabine, which generates 5-fluorouracil selectively in

tumors by enzymes concentrated in human liver and cancer tissue. Eur J Cancer 34: $1274-1281$

Murad AM, Santiago FE, Prtroianu A, Rocha PR, Rodrigues MA, Rausch M (1993) Modified therapy with flourouracil doxorubicin and methorexate in advanced gastic cancer. Cancer 72: 37-41

Neri B, Pantaleo P, Griommoni E, Grifoni R, Paoletti C, Rotella V, Pantalone D, Taddei A, Mercatelli A, Tonelli P (2007) Oxaliplatin, 5 -fluorouracil and epirubicin as first line treatment in advanced gastic carcinoma: a phase II study. Br J Cancer 96(7): 1043-1046

Pfeiffer P, Hahn P, Jensen HA (2003) Short-time infusion of oxaliplatin (Eloxatin) in combination with capecitabine (Xeloda) in patients with advanced colorectal cancer. Acta Oncol 42: 832-836

Pfeiffer P, Sorbye H, Ehrsson H, Fokstuen T, Mortensen JP, Baltesgard L, Tveit KM, Øgreid D, Starkhammar H, Wallin I, Qvortrup C, Glimelius B (2006) Short-time infusion of oxaliplatin in combination with capecitabine (Xelox30) as second line therapy in patients with advanced colorectal cancer after faliure to irinotecan and 5-fluorouracil. Ann Oncol 33: 70-74

Pyrhonen S, Kuitunen T, Nyandoto P, Kouri M (1995) Randomized comparised of fluorouracil, epidoxorubicin, and methotrexate (FEMTX) plus surportive care with surportive care alone in patients with nonresectable gastric cancer. $\mathrm{Br}$ J Cancer 71: 587-591

Raymond E, Faivre S, Coundray AM, Louvet C, Gespach C (2001) Preclinical studies of oxalilpatin in combination chemotherapy. Bull Cancer 88(Spec. No.): 26-34

Ross P, Nicolson M, Cunningham D, Valle J, Seymour M, Harper P, Price T, Anderson H, Iveson T, Hickish T, Lofts F, Norman A (2002) Prospective randomized trial comparing mitomycin, cisplatin, and protracted venous-infusion fluorouracil (PVI 5-FU) with epirubicin, cisplatin, and PVI 5-FU in advanced esophagogastric cancer. J Clin Oncol 20: $1996-2004$

Van Cutsem E, Moiseyenko VM, Tjulandin S, Majlis A, Constenla M, Boni C, Rodrigues A, Fodor M, Chao Y, Voznyi E, Risse ML, Ajani JA, V325 Study Group (2006) Phase III study of docetaxel and cisplatin plus fluorouracil compared with cisplatin and fluorouracil as first line therapy for advanced gastric cancer: a report of the V325 Study Group. J Clin Oncol 24: 4991-4997

Wagner AD, Grothe W, Haerting J, Kleber G, Grothey A, Fleig WE (2006) Chemotherapy in advanced gastric cancer: a systematic review and metaanalysis based on aggregate data. J Clin Oncol 24: 2903-2909

Waters JS, Norman A, Cuningham D, Scarffe JH, Webb A, Harper P, Joffe JK, Mackean M, Mansi J, Leahy M, Hill A, Oates J, Rao S, Nicolson M, Hickish T (1999) Long-term survival after epirubicin, cisplatin and fluorouracil for gastric cancer: results of a randomized trial. Br J Cancer 80: $269-272$

Webb A, Cunningham D, Scarffe JH, Harper P, Norman A, Joffe JK, Hughes M, Mansi J, Findlay M, Hill A, Oates J, Nicolson M, Hickish T, O’Brien M, Iveson T, Watson M, Underhill C, Wardley A, Meehan M (1997) Randomized trial comparing epirubicin, cisplatin and fluorouracil, doxorubicin and methotrexate in advanced esophagogastric cancer. J Clin Oncol 15: 261-267 